\title{
Does a positive lymphocyte cross- match contraindicate living-donor liver transplantation?
}

\section{$\operatorname{AUTHOR}(\mathrm{S})$ :}

Hori, Tomohide; Uemoto, Shinji; Takada, Yasutsugu; Oike, Fumitaka; Ogura, Yasuhiro; Ogawa, Kohei; MiyagawaHayashino, Aya; ... Hori, Yukinobu; Chen, Feng; Egawa, Hiroto

\section{CITATION:}

Hori, Tomohide ...[et al]. Does a positive lymphocyte cross-match contraindicate living-donor liver transplantation?. Surgery 2010, 147(6): 840-844

\section{ISSUE DATE:}

2010-06

URL:

http://hdl.handle.net/2433/120345

\section{RIGHT:}

C 2010 Elsevier B.V.; この論文は出版社版でありません。引用の際には 出版社版をご確認ご利用ください。; This is not the published version. Please cite only the published version. 


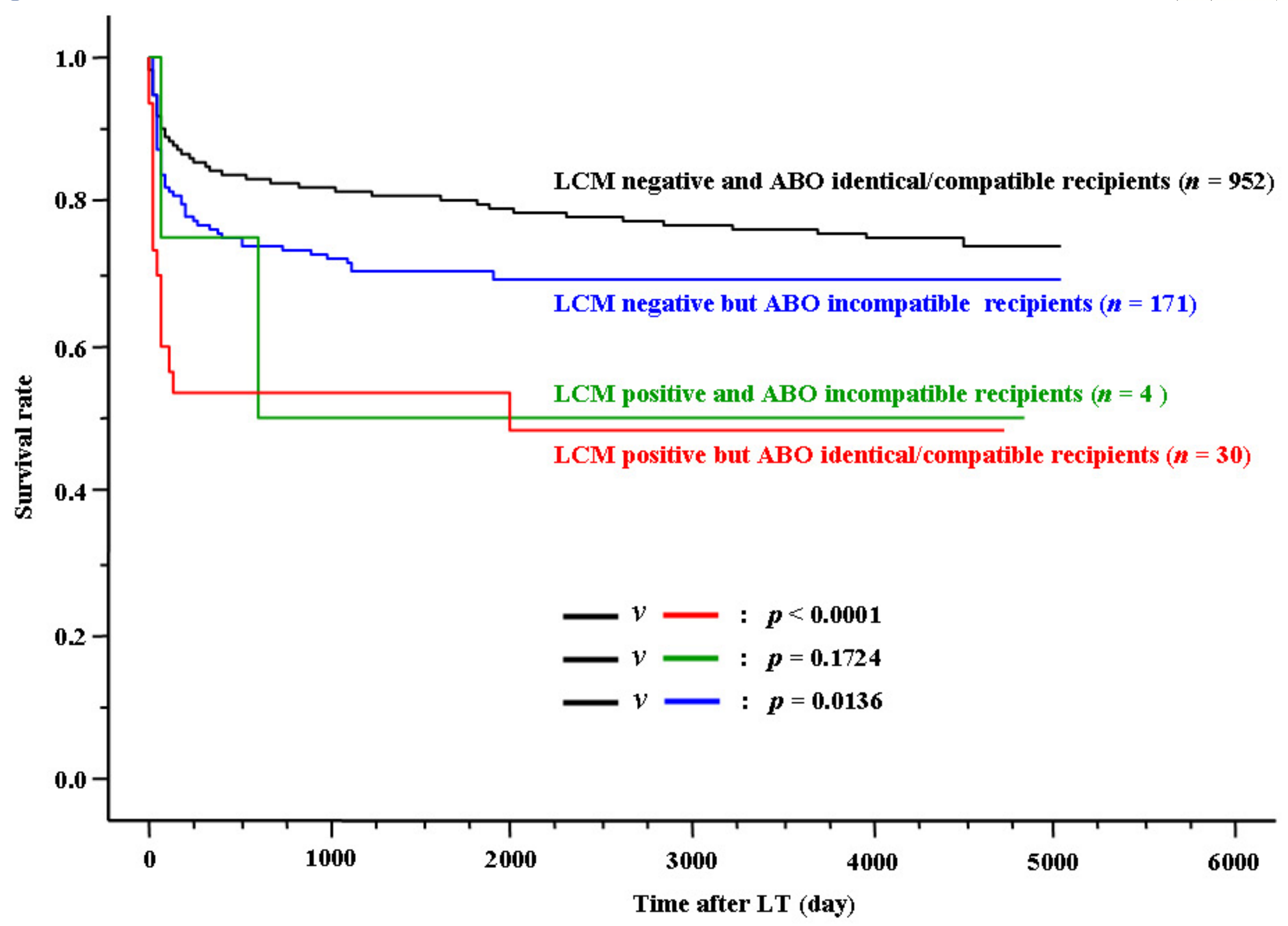


Table 1. Univariate and multivariate analyses of each factor for LDLT outcomes

Univariate analysis

Early deaths after LDLT $(n=276)$

LCM-positive and ABO-identical/compatible

LCM-negative and ABO-incompatible

LCM-positive and ABO-incompatible

vs. LCM-negative and ABO-identical/compatible

$p$ values

vs. LCM-negative and ABO-identical/compatible

vs. LCM-negative and ABO-identical/compatible

$0.0119 *$

0.2886

0.5568

\section{Multivariate analysis}

Factors before and during LDLT for the outcomes $(n=1157)$

Recipient age (years)

Disease (benign vs. malignant)

MELD/PELD scores (points)

LCM (positive vs. negative)

ABO compatibility (incompatible vs. identical/compatible)

Donor age (years)

Cold ischemic time (min)

Operative time (min)

Blood loss (ml)

GRWR

Effects of LCM and ABO compatibilities on the survival rates after LDLT ( $n=1121)$

LCM (positive vs. negative)

ABO compatibility (incompatible vs. identical/compatible)

Synergetic effect between both factors $p$ values

$$
\begin{gathered}
<0.0001 * \\
<0.0001 * \\
<0.0001 * \\
0.0320 * \\
0.0010 * \\
0.1534 \\
0.3375 \\
0.2390 \\
0.0601 \\
0.0004 * \\
\\
0.0006 * \\
<0.0001 * \\
0.1755
\end{gathered}
$$

Note: *Statistically significant $(p<0.05)$.

Abbreviations: GRWR, graft-recipient weight ratio; LCM, lymphocyte cross-match; LDLT, living-donor liver transplantation; MELD, model for end-stage liver disease; PELD, pediatric end-stage liver disease. 